

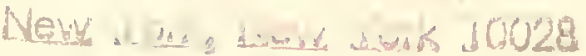








\section{PETER COOPER HEWITT}

IN MEMORIAM 


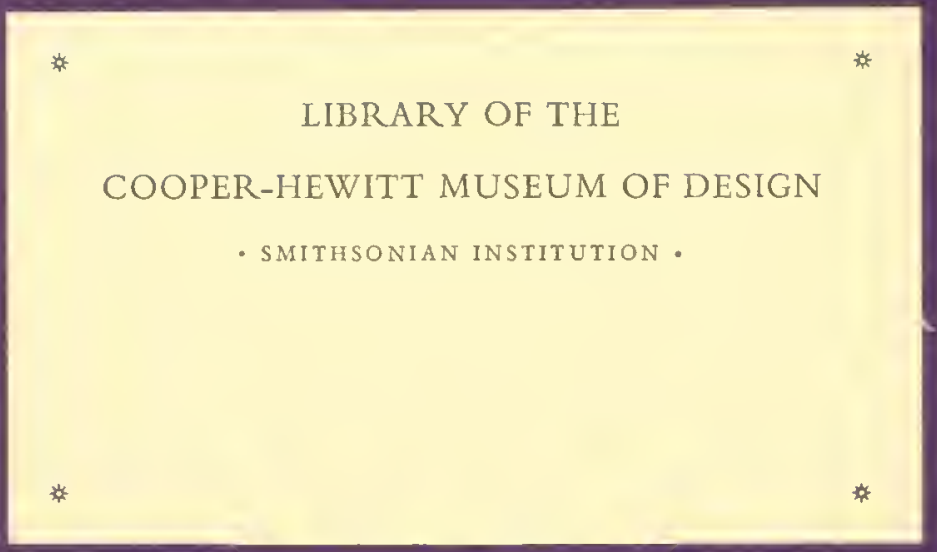





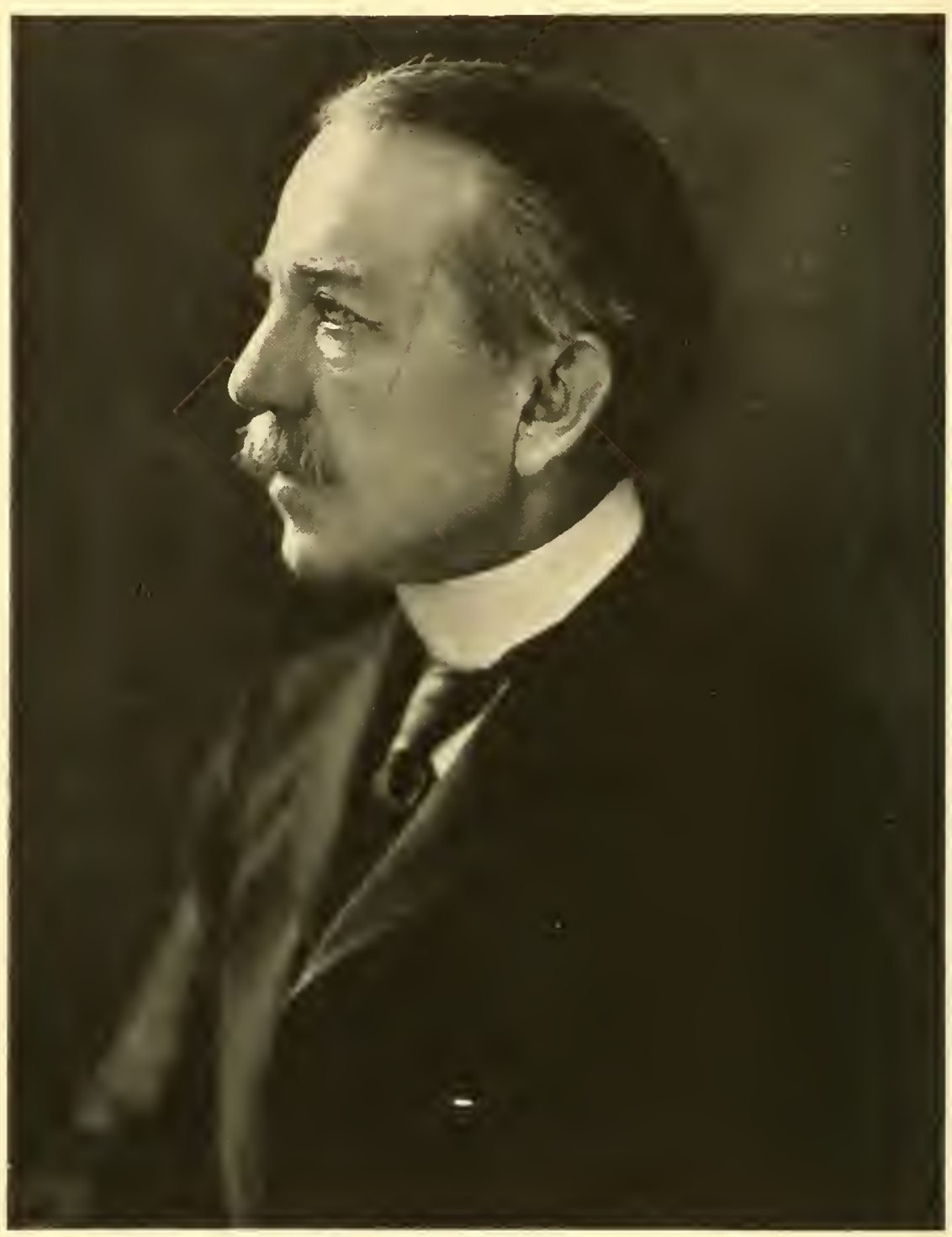




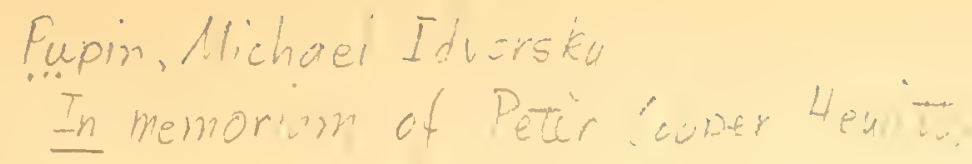

IN MEMORIAM

OF

PETER COOPER HEIVITT

BY

MICHAEL PUPIN, PH.D., SC.D., LL.D.

COLUMBIA UNIVERSITY

$\mathrm{P}$

ETER COOPER was one of the great men of the day when I came to this country as an immigrant boy, forty-eight years ago. He was one of the group of Americans represented in a picture called "Men of Progress" which I first saw at Cooper's Union, many years ago. Soon after that I saw the great man himself in person during one of his frequent visits to Cooper's Union, an institution which he founded, in whose welfare he was deeply interested, and to which he devoted much of his personal attention. I was enrolled in the evening classes of this institution and made much use of its Library. 1 made every effort to understand the character and the life of its distinguished Founder. Little I thought at that time that some day in the distant future his talented and famous grandson, Peter Cooper Hewitt, would become one of my dearest friends.

The impression which. Peter Cooper Hewitt made upon me when I first met him, twenty-five years ago, 
suggested a strong resemblance to his distinguished grandfather, Peter Cooper. But there were many elements in Peter Cooper Hewitt's personality which I did not understand; they puzzled me, but they fascinated me. He was not an ordinary man in any sense of the word. What he said was not easily understood at first, and what he did was apparently even more inaccessible to the understanding of people who did not know him personally. It was puzzling, almost mystifying. But both the way he managed his words and the method he pursued in his work were fascinating and arrested attention. It took me some little time to become familiar with his unusual ways of saying and doing things, and then, finally, he became as clear as the dewdrop of a summer morning.

Peter Cooper Hewitt's personality both as man and as scientist could not be completely understood without understanding first the history of his life, and the history was unique. It is a record of unusual training producing extraordinary results. From his grandfather, Peter Cooper, he inherited a genius for mechanisms. His natural tendency in this direction was encouraged in every respect both by his grandfather and by his parents, the late Abram S. Hewitt and his wife, who was Peter Cooper's only daughter. In the homestead on Lexington Avenue Peter Cooper installed a workshop in an old greenhouse in the yard for the practice of the useful arts and crafts like carpentry, forging, lathe work, turning, etc. In this historic shop he gave his grandchildren their first practical training, providing master mechanics to carry out his own ideas in this 
matter. This was the first training school in which Peter Cooper Hewitt enjoyed the guiding hand of his illustrious grandfather. This was the beginning of that end which made Hewitt a skilled workman in many of the mechanical arts. No practical mechanical problem requiring skill and dexterity was ever known to embarrass him. Many stories are told in the Hewitt family illustrating young Cooper Hewitt's wonderfu] resourcefulness as a mechanician and artisan. His early knowledge of the steamboat, of the steam locomotive, of freight-cars, and of other mechanisms was based upon experience which he gained while building these mechanisms with his own hands. That knowledge was made richer by contributions of his own inventive genius, a genius which he also inherited from his illustrious grandfather. While still a mere boy he informed his father that brakes on cars in a train should all be controlled from a single spot in the train, an idea which a number of years later was put into practice in the Westinghouse air-brake.

His interest in electrical phenomena was stimulated by machines which he himself built, and it was much intensified by Bell's invention of the telephone. Many a telephone instrument he himself made, and, long before the theory of the telephone was completely worked out, he knew, from his personal experience gained in his manufacture of the instrument and from the experiments he performed with it, which were the essential and which the non-essential elements in the construction of a telephone. His knowledge found its way into Hewitt's brains through his hands. Those 
who knew him well and gained that knowledge by watching him at work always felt that a part, at least, of Hewitt's thinking apparatus was in his hands. They seemed to guide his brain, whereas they moved just like the hands of a great piano player, always landing at the correct spot without any apparent guidance from external forces. This precision in the action of his hands manifested itself not only in his scientific experiments, but also in sports and in the manipulation of musical instruments, which he handled with surpassing grace. To watch him skate and dance convinced one that Hewitt's whole body and every part of it showed the same rare grace which one observed in the action of his hands. There was a wonderful rhythm in all of Hewitt's movements. His thinking machinery appeared to be distributed equally over his whole body and not confined to a single part, the brain. The treasures of his mind were stored in every part of his body and not in his brain only.

With ordinary intelligence knowledge starts with abstract principles; it starts with science and ends with art. In the case of Hewitt art came first, as it were by intuition, and its fundamental principles were then derived from it by a sort of mental distillation. Roses first and then the essence of roses. It is not surprising that educational methods such as were practised at the time when Hewitt was a youth could do very little for him. That explains why he never graduated at Stevens Institute, where, as in every other technical school of that time, they paid almost exclusive attention to the abstract sciences of engineering and built up their sub- 
jects by starting from fundamental principles. This was a strange procedure for a youth like Hewitt, and he never became reconciled to it. He admitted, however, that his own method of acquiring knowledge was not applicable to the average youth, and its universal adoption would result in the weeding out of most students of our engineering schools, a result which, in the opinion of many people, might be a blessing.

Hewitt's researches in the electrical science were always his favorite occupation. They began in his early youth and were conducted in his own somewhat unacademic way. His laboratory was not equipped in accordance with ordinary academic ideas which demanded that an electrical laboratory should have in its equipment such and such apparatus and instruments. Hewitt designed his own instruments and apparatus in accordance with the demands of the particular problem which was before him. Often they looked crude to an academically trained eye, but a closer scrutiny revealed the surprising fact that they were just the thing which suited the requirements of the particular investigation, and yielded wonderful results when operated by Hewitt's artistic touch.

Hewitt's mental attitude was that of an inventor, and he was an inventor of the purest type. He was most prolific, but this is not the place nor am 1 qualified to review the long list of his many inventions. No inventor has ever lived who produced more than one epoch-making invention, and the number of those who thus impressed their genius upon their epoch is extremely small. Hewitt is one of this small number. 
His mercury vapor lamp and everything which followed in its wake was epoch-making. Photography, lithography, illumination of docks and factories, and many other uses to which this lamp was put furnish a splendid testimony supporting my statement. To obtain that remarkable result required experimental study of a very high order, and that too in a department of the electrical science which was less developed than any other part of this science. I refer to the motion of electricity through rarefied gases and vapors. He was the first to establish clearly the new physical fact that the reacting force at the negative electrode was the most determining factor in these motions, and he was the first to find a means of overcoming this reaction. When he discovered that, the rest followed as an obvious result.

The Cooper Hewitt mercury vapor lamp was only one of the applications of Hewitt's discovery. The mercury vapor rectifier is a logical sequence of the lamp and not much less important in its technical significance. The rectifying characteristic of electrodes in a rarefied gas is one of the pillars of wireless telephony and telegraphy of to-day. Hewitt was the first to recognize its importance and to employ it in the wireless art; the fact that others obtained a patent for the procedure does not in my opinion prove that others had a priority in the pioneer work which led to the discovery. That priority belongs to Hewitt. I am also in a position to state here without any reservation that Hewitt was the first discoverer of the third or the pilot electrode, usually called the "grid," which, inserted in the path of moving elec- 
tricity in a vacuum tube and suitably electrified, can influence that motion to any extent and in any way we please. That is the backbone of the modern vacuum tube amplifier, which is to-day playing a most eminent part in the modern methods of electrical transmission of intelligence.

In recognition of these splendid achievements Columbia University conferred upon him the honorary degree of Doctor of Science.

Among Hewitt's mechanical inventions which I must mention here, even if only very briefly, is his helicopter, a flying-machine which rises up perpendicularly and soars with perfect steadiness at any height. Hewitt developed this machine in partnership with the late Professor F. B. Crocker, of Columbia University. All the calculations and all the experimental data, obtained from a full-sized model, were completed and ready for use, when suddenly Crocker died in June, and Hewitt followed him only two months later. I hope that this splendid work will not have been done in vain.

Federal authorities may object to my discussion of the aerrial torpedo. The existence of the thing itself is known and has been referred to in the public press. That which is not known is the fact that Hewitt, as a member of the Naval Consulting Board, was the inventor of this wonderful instrument of war.

The inventor of the highest type is a man of imagination and of artistic taste. Hewitt was lavishly equipped with both of these heavenly gifts. Hence as a companion and as a host he was unsurpassed. To be a guest in his artistic home was a treat never to be for- 
gotten. It was a home where art, science, spirituality, and everything which represents the best elements of our American civilization were harmoniously blended. Peter Cooper Hewitt was a worthy descendant of his illustrious grandfather, Peter Cooper, and of his brilliant father, the late Abram S. Hewitt. 





